\title{
EDITORIAL
}

\section{Avicenna Journal of Medicine: 5-year milestones}

Birth to 5 years of age is the toddler phase in humans. Such period is vibrant with excitement and steady growth. When a medical journal turns 5 years old, this resembles maturity and is a source of immense delight. Conception of the journal 5 years ago stemmed from the need for a medical journal of the Syrian American Medical Society and the Syrian medical community as a whole. Several goals were in mind: A tool to facilitate publishing and accessing studies and literature by international, Arab, and Syrian researchers and academicians; a portal to publish research articles on a wide scope of medical sciences; and a platform to promote the knowledge, attitudes, and practice of comprehensive healthcare including preventive, therapeutic, and rehabilitative measures of human health.

As the Avicenna Journal of Medicine thrives into its $6^{\text {th }}$ year, the editorial board would like to share with the readers the progress that has been made since it was first launched in July of 2011. With much optimism and exceptional team-work, the journal was able to successfully achieve its 5 years milestone. This achievement is the collective contribution of our valued authors, expert peer-reviewers, and dedicated editors who put their time and efforts toward the sustainable growth of the journal. In addition, we would like to extend our sincere appreciation to the leadership of the Syrian American Medical Society and its members for sponsoring this academic endeavor.

The editorial board currently consists of 16 members from different countries and wide range medical specialties supported by an expanding list of peer-reviewers of more than 300 experts. The total number of authors registered in the journal approaches 850 from around the globe [Figure 1].

During the past 5 years, a total of 18 issues were published containing 113 articles, covering different aspects of basic and clinical research, and spanning a range of medical specialties. These included 36 original studies, 42 case reports, 16 review articles, and 19 editorials and brief reports [Figure 2].

These articles were carefully reviewed and accepted out of a total of 980 manuscripts submitted to the journal with an average acceptance rate of $11 \%$. Accepted articles were meticulously scrutinized and peer-reviewed by expert referees and editors in strict compliance with publication ethics. The increasing trend of daily journal access, [Figure 3] monthly articles downloads [Figure 4] over the years and the rate of citations of articles per year reflect the scientific value

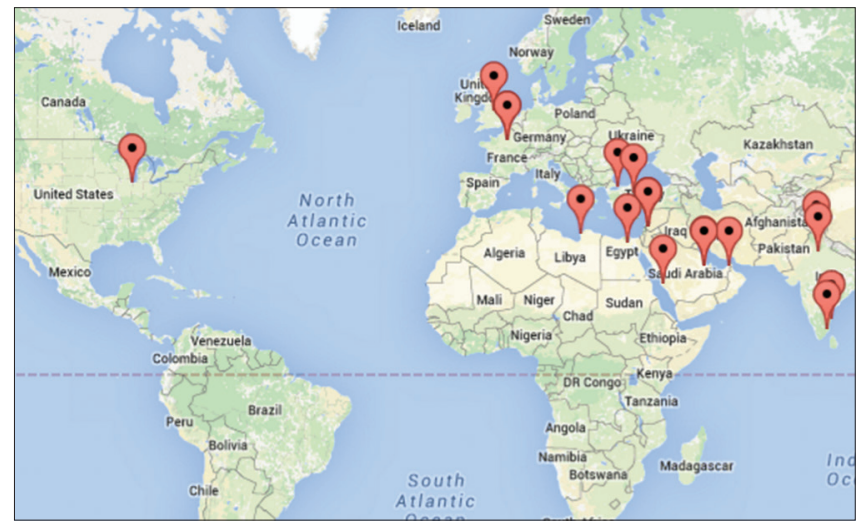

Figure 1: A map showing the geographic distribution of registered authors in the Avicenna Journal of Medicine

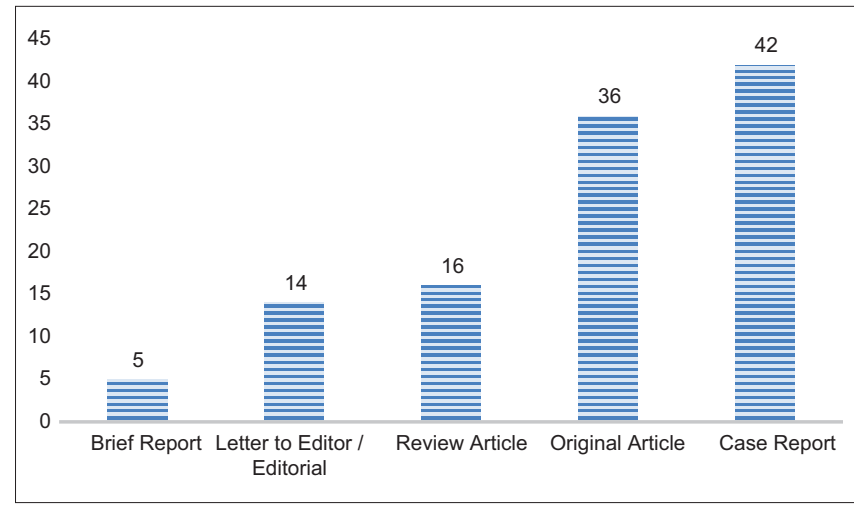

Figure 2: Bar chart display of the number of each type of manuscripts published in the journal at the end of 2015

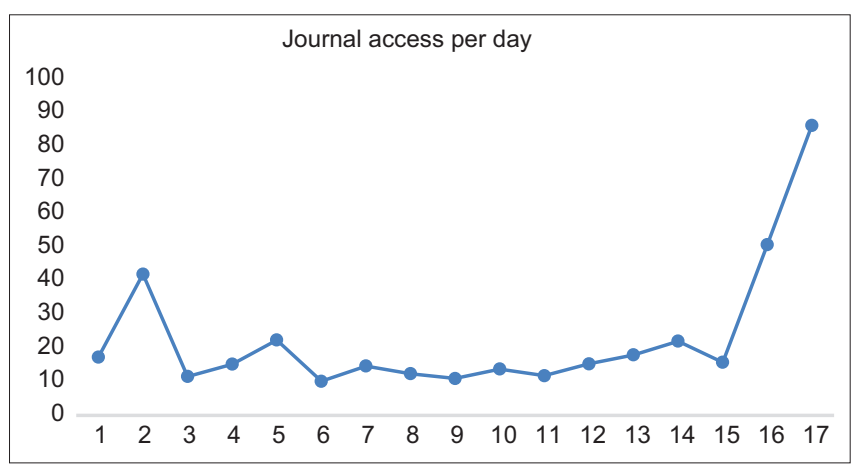

Figure 3: Journal website access per day for each issue published since 2011

and impact of the journal. PubMed indexing of the journal at the end of 2012 was a pivotal milestone that put the journal among its peers in the National Library of Medicine database.

In keeping with the vision set forth by the editorial board, the journal maintains an open-access policy without any 


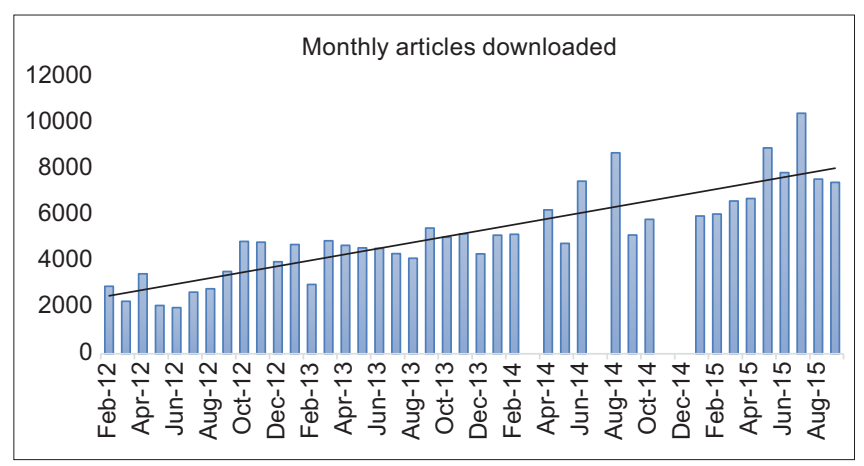

Figure 4: Monthly articles download shows increasing trend since 2011

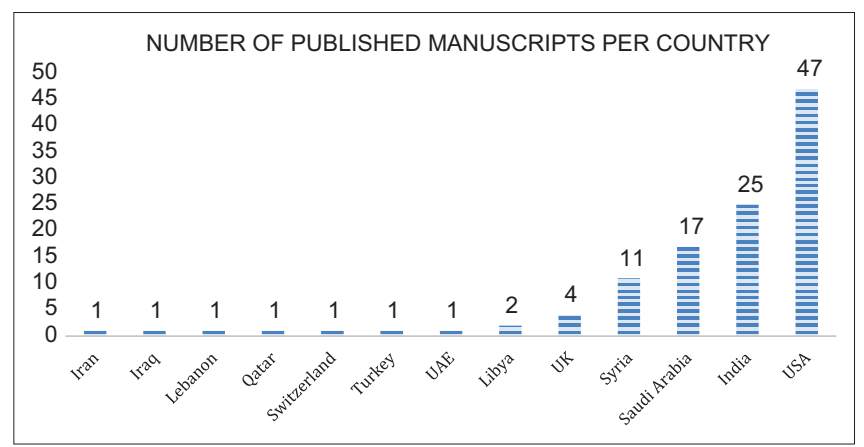

Figure 5: Bar chart of the number of published manuscripts per first authors' countries

submission or publication fees as well as a free worldwide online access to the journal contents. This policy facilitated a wide pool of readership as well as authorship from different continents of the globe [Figure 5].

While the journal seeks to enhance biomedical research in the Arab world, a particular focus is to promote research and editorial skills among Syrian researchers. A total of 11 publications appeared in the journal from different Syrian academic and health institutions. In addition, Syrian researchers practicing in other countries authored numerous valuable publications. Furthermore, the journal was officially endorsed by the Al-Baath University in Syria in 2013 as a peer-reviewed scientific journal for the purposes of academic promotion. Reflecting the ongoing changes in the region, the journal published landmark studies highlighting refugees and war medicines. ${ }^{[1-7]}$

Unfortunately, the impact of the current conflict in Syria on the academic process has evidently hindered research performance and output. As several studies indicated the need for increasing research productivity by Syrian institutions, ${ }^{[8,9]}$ we hope that the Avicenna Journal of Medicine plays a central role in achieving this goal. The trust our authors and readers put in the journal's leadership constantly urges us to work on all possible fronts to bring the journal further to their expectations to be among the leading journals in the world and continue to revive our fading legacy.
Mohammad Arabi, Bassel Atassi ${ }^{1}$, Abdulrahman Masrani ${ }^{2}$, Fares Alahdab ${ }^{3}$, Ahmad Al-Moujahed4, Haitham Arabi ${ }^{5}$

Department of Radiology, King Fahad National Guard Hospital, King Abdulaziz Medical City, Riyadh, Saudi Arabia, ${ }^{1}$ Hematology and Clinical Oncology Section, The Cancer Center at Little

Company of Mary Hospital, ${ }^{2}$ Department of Interventional Radiology, Rush University Medical Center, Chicago, IL, ${ }^{3}$ Mayo Evidence-based Practice Center, Kern Center for Science of Healthcare Delivery, Knowledge Synthesis Program, Mayo Clinic, Rochester, MN, ${ }^{4}$ Massachusetts Eye and Ear Infirmary, Department of Ophthalmology, Harvard Medical School, Boston, MA, USA, ${ }^{5}$ Department of Pathology and Lab. Medicine, King Khaled National Guard Hospital, King Abdulaziz Medical City, Jeddah, Saudi Arabia

Address for correspondence: Dr. Mohammad Arabi,

Department of Medical Imaging, King Abdulaziz Medical City, P.O. Box 22490, Riyadh 11426, Kingdom of Saudi Arabia. E-mail: marabi2004@hotmail.com

\section{REFERENCES}

1. Al-Makki A, Rifai AO, Murad L, Zanabli AR, Kayal A, Soudan K, et al. The syrian national kidney foundation: Response for the need of kidney patients during the crisis. Avicenna J Med 2014;4:54-7.

2. Alahdab F, Omar MH, Alsakka S, Al-Moujahed A, Atassi B. Syrians' alternative to a health care system: "Field hospitals". Avicenna J Med 2014;4:51-2.

3. Alghothani N, Alghothani Y, Atassi B. Evaluation of a short-term medical mission to Syrian refugee camps in Turkey. Avicenna J Med 2012;2:84-8.

4. Khayata I, Bourque J. Mobile anesthesia: Ready, set, pack, and go. Avicenna J Med 2012;2:40-4.

5. Kherallah M, Alahfez T, Sahloul Z, Eddin KD, Jamil G. Health care in Syria before and during the crisis. Avicenna J Med 2012;2:51-3.

6. Sahlool Z, Sankri-Tarbichi AG, Kherallah M. Evaluation report of health care services at the Syrian refugee camps in Turkey. Avicenna J Med 2012;2:25-8.

7. Sankari A, Atassi B, Sahloul MZ. Syrian field hospitals: A creative solution in urban military conflict combat in Syria. Avicenna J Med 2013;3:84-6.

8. Alhamid N, Almounayer N, Alsabbagh B, Atassi B. Case reports and research productivity among Syrian medical students: Review, reality, and suggested solutions. Avicenna J Med 2015;5:101-5.

9. Diab MM, Taftaf RM, Arabi M. Research productivity in Syria: Quantitative and qualitative analysis of current status. Avicenna J Med 2011;1:4-7.

This is an open access article distributed under the terms of the Creative Commons Attribution-NonCommercial-ShareAlike 3.0 License, which allows others to remix, tweak, and build upon the work non-commercially, as long as the author is credited and the new creations are licensed under the identical terms.

\begin{tabular}{|l|l|}
\hline \multicolumn{2}{|c|}{ Access this article online } \\
\hline Quick Response Code: & \\
\hline
\end{tabular}

Cite this article as: Arabi M, Atassi B, Masrani A, Alahdab F, Al-Moujahed A, Arabi H. Avicenna Journal of Medicine: 5-year milestones. Avicenna J Med 2016;6:1-2. 